\title{
Flexible and fixed partitions in freestalls-Effects on lying behavior and cow preference
}

\author{
L. E. Ruud ${ }^{1}$ and K. E. Bøe \\ Department of Animal and Aquacultural Sciences, Norwegian University of Life Sciences, N-1432 Ås, Norway
}

\begin{abstract}
The objective was to investigate the effect of stall partition design on total lying time, lying position, and stall cleanliness, and to evaluate the preferences of cows regarding stalls with traditional fixed stall dividers or flexible stall dividers. Using a crossover design, 16 nonlactating dairy cows were housed singly for $9 \mathrm{~d}$ in pens with 2 freestalls, 1 with fixed cantilever dividers and 1 with flexible dividers. The cows were first given access to one stall type, and then to the other type of stall, and finally to both in a preference test. Type of stall divider did not influence lying behavior $(13.5 \mathrm{~h}$ for fixed versus $14.0 \mathrm{~h}$ for flexible, $\pm 0.4 \mathrm{~h}$ ), lying positions, or stall cleanliness; however, the cows showed a preference for lying in the flexible stalls (65.2 for flexible vs. 34.8 for fixed $\pm 8.2 \%$ ). This indicated that cows are able to distinguish between type of stall divider and that it is important to them; however, it is not clear if the reason for this is the shape or the properties of the dividers. We concluded that cattle chose a flexible stall divider over a fixed one, but the long-term consequences of this preference are not clear, because no obvious changes in stall usage were observed when cows were only given access to one type of divider.
\end{abstract}

Key words: freestall, stall divider, stall partition, lying time

\section{INTRODUCTION}

The basic idea of the freestall was to control defecation behaviors of cows to reduce workload and use of bedding (Bramley, 1962). The function of the structural parts of the freestall is to provide the cows with a comfortable place for rest (stall base) and to restrict lengthwise (head and neck rails and brisket locator) and lateral (stall divider) positions and movements. Stall design is of major importance for achieving hygienic conditions, normal lying time, and use of the stall.

Received September 14, 2010.

Accepted June 24, 2011.

${ }^{1}$ Corresponding author: lars.erik.ruud@tine.no
Several studies on freestalls have evaluated stall width and length (Tucker et al., 2004), flooring (Nilsson, 1988; Fulwider and Palmer, 2004; Ruud et al., 2010a), neck rail (Tucker et al., 2005; Fregonesi et al., 2009), head rails (Veissier et al., 2004), brisket locator (Tucker et al., 2006), and use of bedding (Wander, 1979; Tucker and Weary, 2004). Thus, the design of the major parts of freestalls is well described. The situation regarding freestall dividers is different, as the development appears to be industry driven. In general, the knowledge on effects of stall divider design on lying behavior, cleanliness, and preference is limited. One exception is O'Connell et al. (1992), who compared an old, enclosed type of divider ("Newton Rigg") with more open cantilever dividers ("Dutch Comfort") and found that the occupancy rate increased with the latter type of divider.

The function of the freestall partitions is to separate cows while lying, define the place for lying, guide the cow when entering or exiting a stall, protect her while resting (Gamroth and Stokes, 1999), and prevent her from turning in the stall (Irish and Merrill, 1986). These functions should be performed without causing injury or entrapment, and space needed for normal lying down and rising behavior should be available (Fregonesi et al., 2009). If the forward lunge movement of the cow is obstructed, it is important that the cow can side lunge when rising; however, it could be argued that this is a less preferred alternative compared with straight forward rising (McFarland and Graves, 1995). In a side lunging situation, the upper part of the divider will act as a neck rail; hence, the general recommendation is that the height of the divider should be approximately as high as the neck rail (Anderson, 2008). The lower part of the divider rail should allow some space for legs and the udder (CIGR, 1994). The pattern in the development of freestalls and stall dividers is toward a more open construction, allowing normal ascent and descent movements (Anderson, 2008). Diagonal standing and lying are associated with reduced stall cleanliness (Ruud et al., 2011); hence, the position of the cow should ideally be parallel to the long axis of the stall. A fixed stall divider design has been used in the belief that it would make the cows lie straighter in the 
stall, whereas stall design variables restricting the lunge space or standing position, such as head and neck rail position, are what initially forces them to lie diagonally in the stalls.

Rails and freestall components that are yielding reduce the contact pressure to the body and lessen the risk for skin damage (Blom et al., 1984). One may speculate that flexible dividers do not provide enough restriction to prevent cows from turning in the stall or performing other nonpreferred behaviors such as lying more diagonally or defecating in the stall. Wandel and Jungbluth (1997) compared a relatively open freestall design with a free-swinging horizontal wooden plank as a divider to a conventional stall ("English stand") and concluded that simple steering was effective and gentle to the animals. Aland et al. (2009) found that vertically positioned elastic partitions used in tiestalls positively influenced stall cleanliness and lying position, but did not affect lying time. Flexible stall dividers in freestalls are new and we know of no study that has investigated their effects on activity, lying position, and hygiene. The objective was to investigate effects of stall partition design on total lying time, lying position, and stall cleanliness, and on cow preferences regarding stalls with fixed or flexible stall dividers.

\section{MATERIALS AND METHODS}

\section{Experimental Design}

Using a crossover design, 4 replicates of 4 nonlactating dairy cows ( $\mathrm{n}=16$ cows) were housed singly for $9 \mathrm{~d}$ in pens with 2 freestalls, 1 with fixed cantilever dividers (hereafter, fixed) and 1 with flexible dividers (hereafter, flexible). A solid gate was used for blocking the stalls not in use during a treatment period. Cows were selected pairwise according to parity and shoulder height and were equally distributed between treatments. In period 1 ( $4 \mathrm{~d})$, half of the cows had access only to the fixed freestall, while the other half had access only to the flexible freestalls, and the cows were switched to the opposite treatment in period $2(4 \mathrm{~d})$. In period 3 $(1 \mathrm{~d})$, all cows had free access to both freestalls in a preference test. The adjustment period before observing behavior in restriction periods 1 and 2 was $2 \mathrm{~d}$; it could not be longer due to management reasons on the university farm.

\section{Experimental Pens and Freestall Design}

Four experimental pens were established in an insulated, mechanically ventilated room with an ambient indoor air temperature of $7.5 \pm 2.7^{\circ} \mathrm{C}$ (mean $\pm \mathrm{SD}$ ). In each pen ( 6.50 by $3.60 \mathrm{~m}$ including the freestalls)

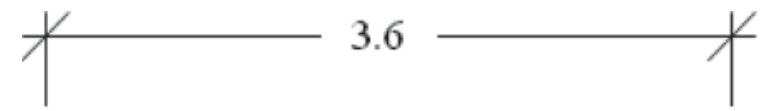

- $0.4-1.2-0.4-1.2-0.4$

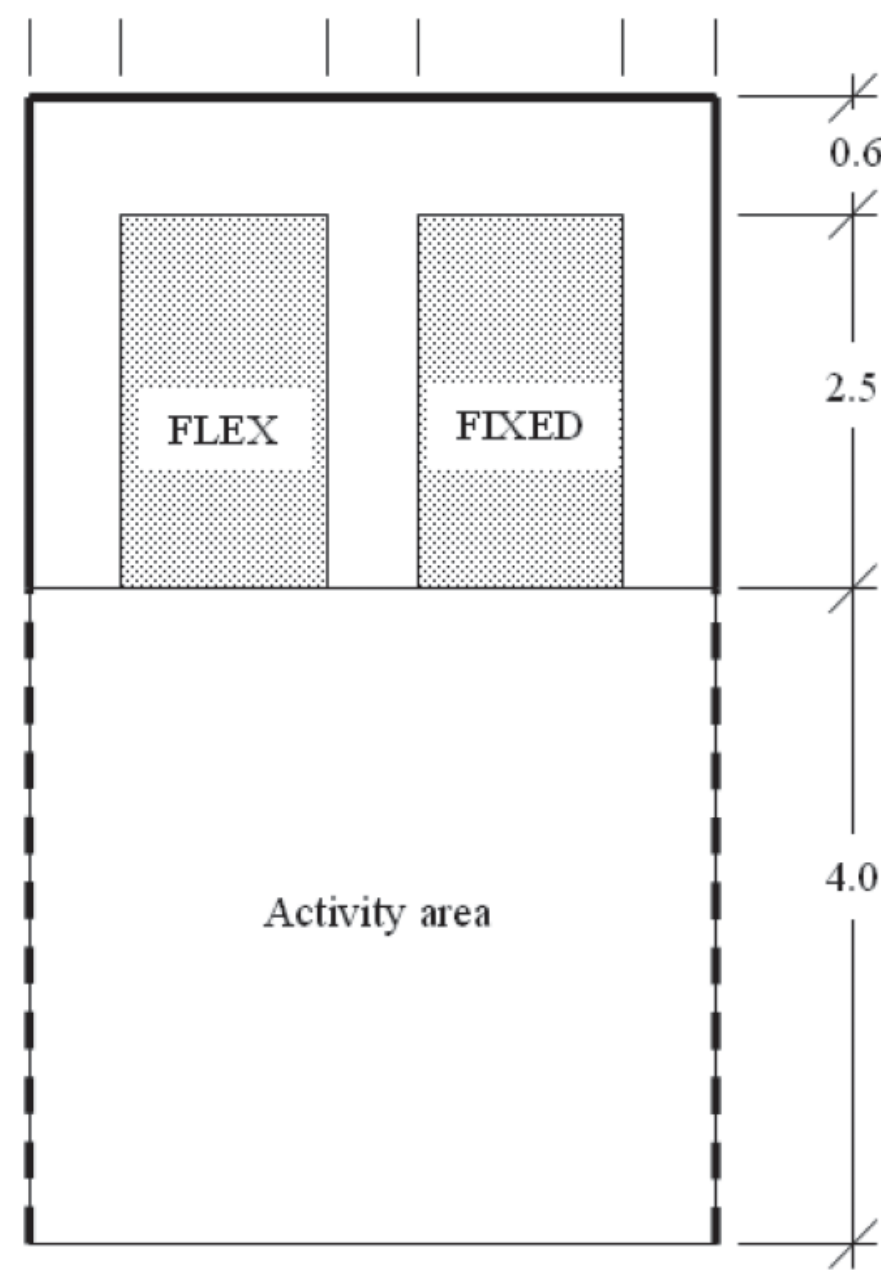

Feeding table

Figure 1. The study cows were singly housed in experimental pens with 1 freestall with flexible stall dividers (FLEX) and 1 stall with looped steel pipeline dividers (FIXED).

were 2 freestalls (Figure 1), one of each type, equally allocated on the left or right side in the pens.

Solid walls were present between each pen in the freestall area to minimize the influence of social ranking on lying behavior. In the activity area, a simple gate consisting of 2 horizontal bars separated the pens. All freestalls measured $1.20 \times 2.40 \mathrm{~m}$, with $0.40 \mathrm{~m}$ of free space on each side of the stalls. All stalls were equipped with the same M35R mattresses from DeLaval (Tumba, Sweden). To optimize freestall cleanliness, data from a cross-sectional field study in 232 herds on freestall design from Ruud et al. (2010b, 2011) were used to determine the position of head and neck rails and the 
brisket locator. The stall base sloped $2 \%$ backward, a brisket locator $(0.10 \mathrm{~m}$ high) was located $1.82 \mathrm{~m}$ from rear curb, and there was no lower head rail. The upper head rail was located $2.35 \mathrm{~m}$ from the rear curb (horizontally) and $0.85 \mathrm{~m}$ above the floor, and a neck rail (steel pipeline, $50 \mathrm{~mm}$ in diameter) was located on a diagonal $2.00 \mathrm{~m}$ from the rear curb and $1.09 \mathrm{~m}$ above the top of the mattresses. The height of the rear curb was $0.25 \mathrm{~m}$. The fixed divider was a commercial, standard pipeline divider (CC1800; De Laval), whereas the flexible divider was made of a straight glass fiber rod (40 $\mathrm{mm}$ in diameter) with an external PVC sleeve (Freedom stall, J\&D Manufacturing, Eau Claire, WI; Figure 2). The length of the rod was $2.40 \mathrm{~m}$ and it was attached in a bracket on the floor in front of the brisket locator. The height of the rear end of the rod was 1.08 $\mathrm{m}$ above the rear curb.

\section{Animals and Management}

The 16 nonlactating, healthy dairy cows of the Norwegian Red dairy breed had completed $2.8 \pm 1.4$ lactations and had $37.7 \pm 9.2 \mathrm{~d}$ left until expected calving, calculated at $d 1$ of the experiment. Mean shoulder height was $1.35 \pm 0.03 \mathrm{~m}$, which is close to the mean for this breed (Nygaard, 1983; Sveberg et al., 2007). All cows came from the university herd and were previously housed in a freestall housing system with fixed, cantilever steel pipeline stall dividers. The cows were randomly allocated to pen. The animals were fed grass silage for ad libitum consumption twice daily at 0800 and $1630 \mathrm{~h}$, and water was available continuously. The stalls and pens were cleaned immediately after each feeding and only a limited amount of fine sawdust (approximately $0.2 \mathrm{~L}$ ) was added to ensure the visibility of the grid lines on the mattresses.

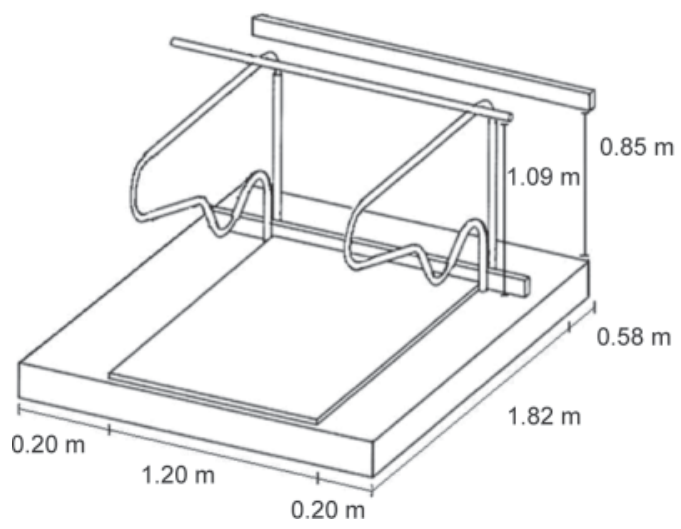

\section{Behavioral Observations}

A digital video camera was located above each freestall and connected to a computer with a digital surveillance system from MSH Video software (MSH Video, Riga, Latvia). Artificial lights were on $24 \mathrm{~h} / \mathrm{d}$. To score the position of the cows when lying in the stall, gridlines with $0.1 \mathrm{~m}$ spacing were painted on the floor in the rearmost meter of the stall and extending $0.4 \mathrm{~m}$ to either side of the stall. The cows were video-recorded the last $2 \mathrm{~d}$ of periods $1(48 \mathrm{~h})$ and $2(48 \mathrm{~h})$ and the entire period $3(24 \mathrm{~h})$. The body positions in the stall as well as the activities were recorded every 10th min (instantaneous sampling) using the following ethogram.

Activity (Periods 1 and 2). Activity was recorded as cows were (1) lying in the stall, (2) standing with 2 feet in the stall, (3) standing with 4 feet in the stall, or (4) standing in the activity area.

Lying Position (Periods 1 and 2). Lying position was observed for cows when using the freestalls and recorded as follows: (1) the lateral position was the greatest distance horizontally from the outermost body part to the lateral stall border; (2) the lengthwise position was the horizontal distance from rear curb to the root of the tail (basis caudae); (3) the angle of the cows relative to the length axis of the stall was (a) cows lying straight in the stall and without any contact between the cow and the stall divider, (b) cows lying straight in the stall and with contact between cow and stall divider, (c) cows lying with either shoulder (scapulae crista) or hip (tuber coxae) in contact with stall divider, or (d) cows lying with shoulder and hips in contact with stall dividers on opposite sides; and (4) the head posture in relation to body was when lying in the stall as (a) straight forward, (b) to the side, or (c) backward in contact with the body (Figure 3).

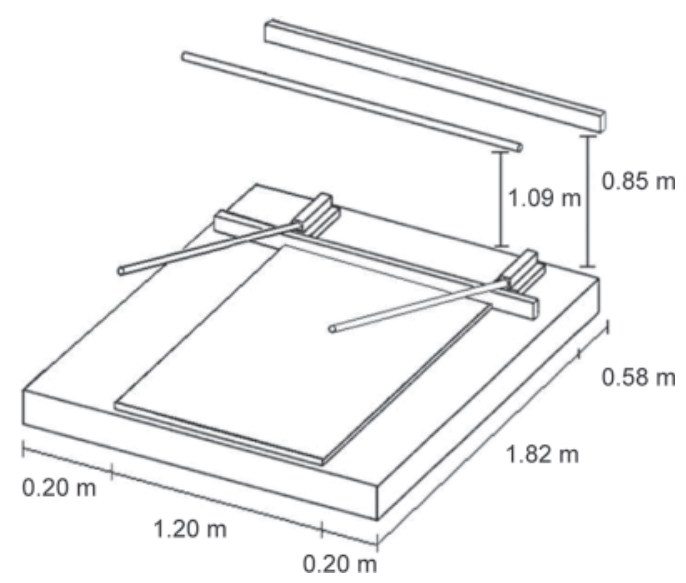

Figure 2. The freestalls used in the present study were the De Laval CC 1800 freestall (DeLaval, Tumba, Sweden; left) and the Freedom stall (J\&D Manufacturing, Eau Claire, WI; right). 


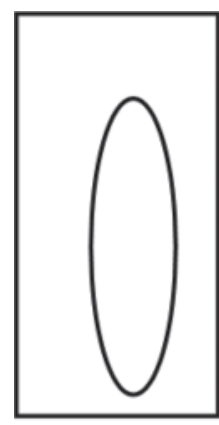

a)

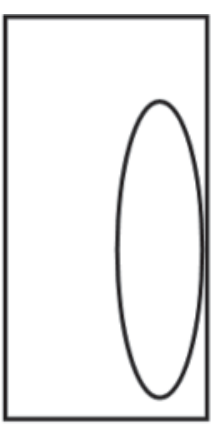

b)

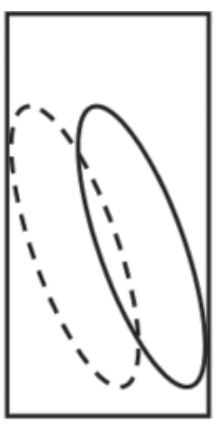

c)

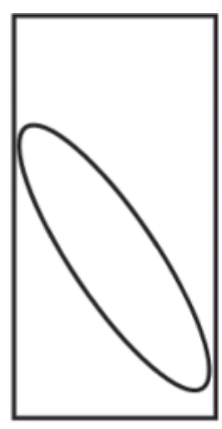

d)
Figure 3. The angle of the cows relative to the length axis of the stall was recorded as (a) cows lying straight in stall without contact between cow and stall divider; (b) cows lying straight in stall with contact between cow and stall divider; (c) cows lying with either shoulder or hip in contact with stall divider; or (d) cows lying with shoulder and hip in contact with stall dividers on opposite sides.

Preference Test (Period 3). In the preference test, the behavior of each cow was scored every 10th minute into one of the following categories: (1) lying in the flexible stall, (2) standing with 2 or 4 feet in the flexible stall, (3) lying in the fixed stall, (4) standing with 2 or 4 feet in the fixed stall, or (5) standing in the activity area. The first stall where a cow laid down for a minimum of 2 subsequent observations after the morning feeding in period 3 was regarded as that cow's preferred first choice. If the time an animal spent in one of the stalls exceeded half of the total time spent in the stalls, that animal was defined as having a preference for that type of stall.

Stall Cleanliness. The rearmost meter of stall base was divided into 8 sectors of $0.50 \times 0.40 \mathrm{~m}$, including $0.2 \mathrm{~m}$ outside the stall divider. Stall cleanliness was recorded immediately after each feeding as number of cow droppings ( $>0.05 \mathrm{~m}$ in diameter) per stall sector.

\section{Statistical Analysis}

For the statistical analyses, cow was the statistical unit. Based on the recorded data from multiple days per cow and treatment, individual means were first calculated and then used in the analyses. Treatment effects on activity, lying position, and preferences were tested by the one-way paired $t$-test procedure in JMP (version 7.0, SAS Institute Inc., Cary, NC), and all tests had $14 \mathrm{df}$.

\section{RESULTS}

One of the cows lay only in the activity area (i.e., never used any of the freestalls for lying) and was excluded from the data set. All results are based on $\mathrm{n}=$ 15 cows. None of the other cows was observed lying in the activity area.

\section{Activity (Periods 1 and 2)}

The observed lying time was 13.5 to $14.0 \pm 0.4 \mathrm{~h}$ $\mathrm{h} / \mathrm{d}$ (mean $\pm \mathrm{SE}$ ). When comparing fixed and flexible stalls, no differences were found in total lying time, time spent standing in stall with 2 or 4 hooves, or in total standing time $/ 24 \mathrm{~h}(P>0.15$; Table 1$)$.

\section{Lying Position}

A lying position with some part of the body outside the lateral stall border was adopted by almost all cows in both treatments, because more than $95 \%$ of the observations were for cows observed with part of the body outside the stall border. The most prevalent lateral lying position for cows in fixed stalls was from 0.1 to $0.2 \mathrm{~m}$ to the side of the stall border. In flexible stalls, a position $>0.2 \mathrm{~m}$ outside the stall border was prevalent; however, no statistical differences between the treatments were found $(P>0.15$; Figure 4$)$.

Lengthwise lying position resulted in the cows spending more than $75 \%$ of their time lying in a stall with the tail root behind the rear curb of the stall for both treatments. Even though cows were expected to lie more forward in the flexible stalls, no statistical differences were found regarding the lengthwise lying position in the stalls $(P>0.15)$. Regarding the angle of the cow versus stall, cows in both treatments spent 70 to $80 \%$ of the time lying straight in the stall without being in contact with the dividers and 4 to $9 \%$ of the time lying straight in the stall in contact with the divider. No differences were found regarding angle of the cows versus length axis of stall $(P<0.15)$. A tendency $(P<0.08)$ was observed for cows lying diagonally with contact between divider and hip or shoulder (Figure 5). Lying

Table 1. Lying time and time spent standing in stall for fixed or flexible stall dividers $(\mathrm{n}=15$ cows $)$

\begin{tabular}{|c|c|c|c|c|}
\hline Activity & Fixed & Flexible & $\mathrm{SE}$ & $P$-value \\
\hline Lying time, $\mathrm{h} / 24 \mathrm{~h}$ & 13.49 & 13.95 & 0.36 & $>0.15$ \\
\hline Standing with front hooves in stall, $\min / 24 \mathrm{~h}$ & 84.7 & 80.0 & 16.11 & $>0.15$ \\
\hline Standing with 4 hooves in stall, $\min / 24 \mathrm{~h}$ & 26.7 & 20.0 & 9.71 & $>0.15$ \\
\hline Standing in stall, total time, $\min / 24 \mathrm{~h}$ & 111.3 & 100.0 & 16.35 & $>0.15$ \\
\hline
\end{tabular}




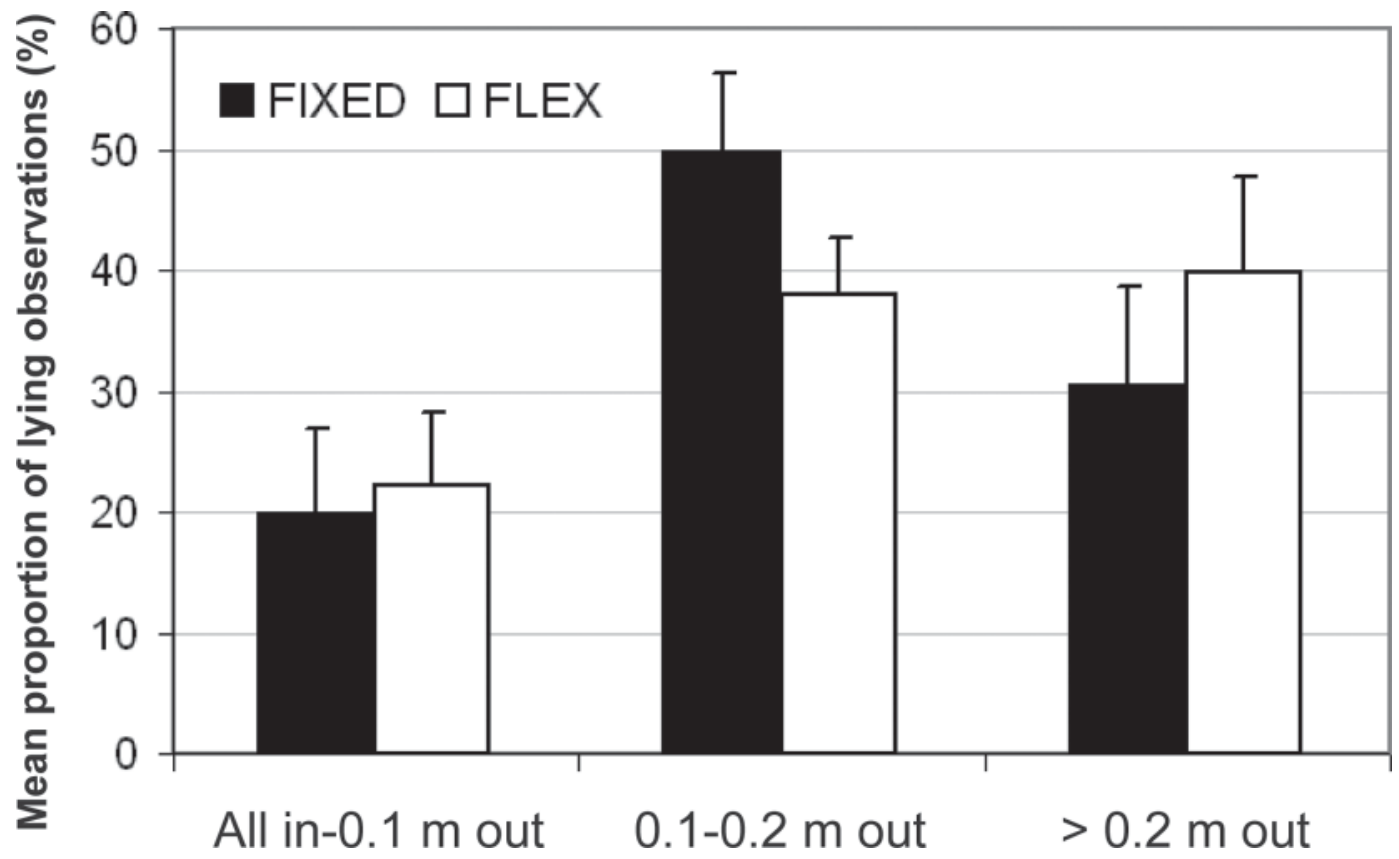

Figure 4. Lateral position of nonlactating dairy cows $(\mathrm{n}=15)$ recorded as the horizontal distance from the most extreme position of a body part to the lateral stall border in freestalls with fixed and flexible dividers, expressed as mean proportion of recorded lying observations (mean $\pm \mathrm{SE})$.

with hip and shoulder in contact with the stall divider at opposite sides was observed occasionally for 3 cows in the flexible treatment.

The cows kept the head straight forward for approximately $30 \%$ of the time they were lying, to the side for $60 \%$, and along the body for the remaining $10 \%$ of the total lying time. Treatment did not influence the positions of the head $(P>0.15)$.

\section{Preference Test (Period 3)}

In the preference test, the cows spent a greater proportion of the time lying in the flexible stalls than in the fixed stalls $(65.2 \%$ vs. $34.8 \% \pm 8.2 \% ; P<0.02)$. Large individual differences were observed (Table 2). Ten cows showed a preference for lying in the flexible stall and 5 cows for the fixed stall. Further, 11 of 15

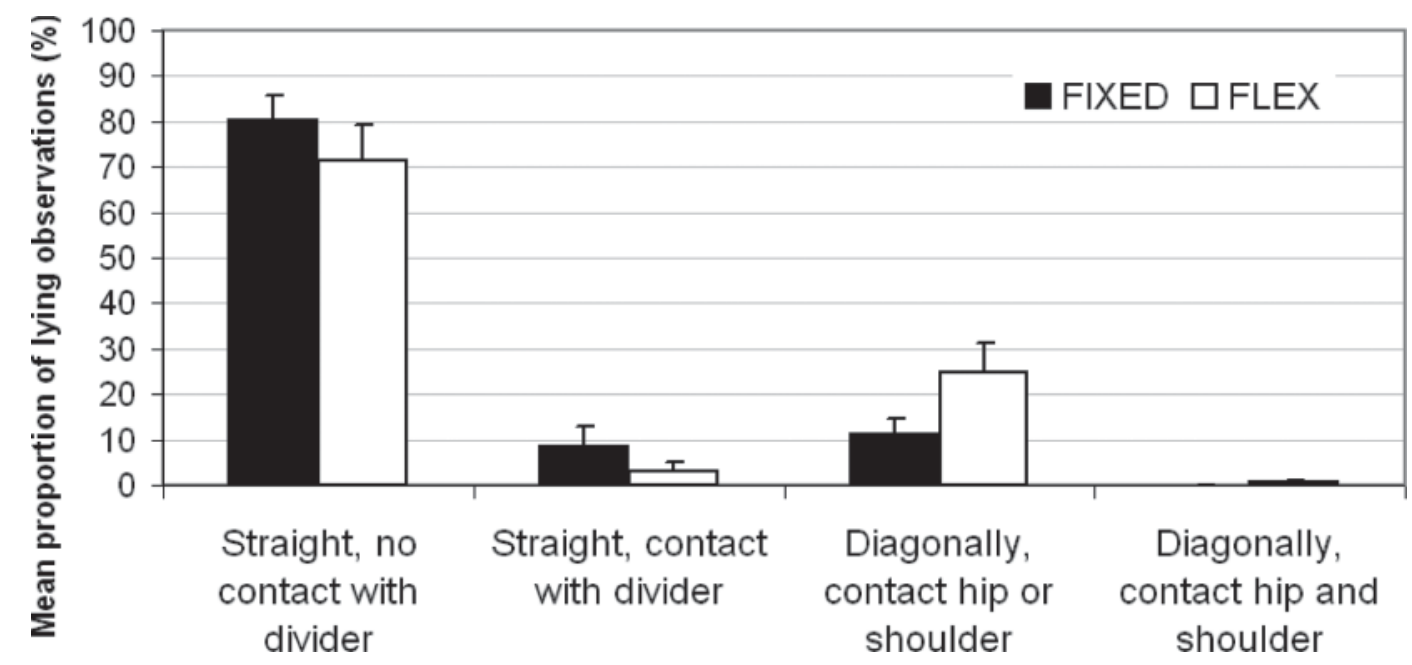

Figure 5. The lying positions of nonlactating dairy cows $(\mathrm{n}=15)$ in freestalls with fixed and flexible dividers recorded as contact with the divider and angle of the cow relative to the length axis of the stall, expressed as mean proportion of recorded lying observations (mean \pm SE). 
Table 2. Preference for freestalls with fixed or flexible stall dividers tested with single-housed nonlactating dairy cows $(\mathrm{n}=15)$ in pens with free access to both types of stalls for a period of $24 \mathrm{~h}$

\begin{tabular}{|c|c|c|c|c|}
\hline \multirow{2}{*}{$\begin{array}{l}\text { Cow } \\
\text { no. }\end{array}$} & \multicolumn{2}{|c|}{ Lying, $\%$ of total lying time } & \multicolumn{2}{|c|}{ Standing, $\%$ of total standing time } \\
\hline & Fixed & Flexible & Fixed & Flexible \\
\hline 1 & 0.0 & $100^{*}$ & 0.0 & $100.0^{*}$ \\
\hline 2 & 48.8 & $51.3^{*}$ & 46.2 & $53.8^{*}$ \\
\hline 3 & 6.7 & $93.3^{*}$ & 8.3 & $91.7^{*}$ \\
\hline 4 & $60.2^{*}$ & 39.8 & $80.0^{*}$ & 20.0 \\
\hline 5 & 17.3 & $82.7^{*}$ & 20.0 & $80.0^{*}$ \\
\hline 6 & $78.1^{*}$ & 21.9 & $66.7^{*}$ & 33.3 \\
\hline 7 & 0.0 & $100^{*}$ & 0.0 & $100.0^{*}$ \\
\hline 8 & 23.7 & $76.3^{*}$ & $62.5^{*}$ & 37.5 \\
\hline 9 & 0.0 & $100^{*}$ & 0.0 & $100.0^{*}$ \\
\hline 10 & 30.1 & $69.9^{*}$ & 15.0 & $85.0^{*}$ \\
\hline 11 & $100^{*}$ & 0.0 & $90.9 *$ & 9.1 \\
\hline 12 & $65.1^{*}$ & 34.9 & $71.4^{*}$ & 28.6 \\
\hline 13 & 12.0 & $88.0^{*}$ & 40.0 & $60.0^{*}$ \\
\hline 14 & $58.2^{*}$ & 41.8 & $75.0^{*}$ & 25.0 \\
\hline 15 & 21.4 & $78.6^{*}$ & 28.6 & $71.4^{*}$ \\
\hline Mean & 34.8 & $65.2^{1}$ & 40.3 & $59.7^{2}$ \\
\hline
\end{tabular}

${ }^{1}$ Preference for lying in flexible stalls $(\mathrm{SEM}=8.2 \% ; P<0.02)$.

${ }^{2}$ Tendency for preferring to stand in flexible stalls $(\mathrm{SEM}=8.3 \% ; P=0.11)$.

*Preferred stall for lying or standing.

cows $(73.3 \%)$ had the flexible stalls as their preferred first choice when lying down after the morning feeding in study period 3. Standing in the stall with 2 or 4 feet represented only $9.0 \%$ of the observations for time spent in the stall. We found that $93.3 \%$ of cows preferring to lie in one particular type of stall also preferred to stand in the same type of stall (pairwise correlation coefficient $=0.90 ; P<0.001 ;$ Table 2$)$.

\section{Stall Cleanliness}

All freestalls stayed clean during the experimental period; only 2 droppings were observed in all the stalls during the study, 1 in flexible and 1 in the fixed stalls. Hence, no analysis on these data was performed.

\section{DISCUSSION}

In present study, no differences in activity, lying positions, or cleanliness were found. Despite that, the majority of the cows preferred the flexible stalls. Investigations on flexible dividers are few; however, the preferences from present study support Gwynn et al. (1991), who found that cows prefer a rope instead of a fixed timber structure as the lower rail of the divider. Further, Wandel and Jungbluth (1997) found that cows prefer a free-swinging wooden plank divider compared with a conventional fixed divider.

As described by Tucker et al. (2003), interpreting the results of preference studies requires attention to several factors such as social factors and previous experiences of the cows. All the cows in present study were housed individually to reduce social influences on their preferences. They went through a restriction period with both types of stalls before the preference test. Results from a preference test will be relative (Tucker et al., 2003) and in the present study, the comparison was made with another modern and open stall design. The yield properties of the dividers are probably of minor importance to lying position, because the physical contact with the dividers in the current study was infrequent (L. E. Ruud, unpublished data). In contrast, Blom et al. (1984) found that cows touched the partitions in a freestall 100 to 150 times per day.

The lying times observed in present study supported the lying time for cows in comfortable freestalls in other studies (Tucker and Weary, 2004). In addition, lying time was similar between treatments, probably because lying time is affected more by the stall base (Wander, 1979; Nilsson, 1988; Manninen et al., 2002) and less so by the stall dimensions (Tucker et al., 2004).

Compared with the results of Tucker et al. (2005), the proportion of time standing with 2 hooves in the stall compared with total stall standing time was relatively high. This may indicate that the neck rail position used in present study was rather restrictive. However, no differences between treatments were found in time standing with front hooves or all 4 hooves, or in total stall standing time. The results regarding lying positions as well as head posture indicated that both dividers performed equally well in positioning the cows. Knowledge on the positions of cows when lying in freestalls is meager; hence, no direct comparison was found in the literature for the findings from present 
study. Veissier et al. (2004) and Tucker et al. (2004, 2005) have reported on stall design without considering lying position.

When using a less restrictive stall construction, one may expect an increased risk for flexible stalls to be contaminated compared with fixed stalls. However, stall type had no negative effect on stall cleanliness in the current study. The very clean stalls in both types of treatment were probably due to the optimized stall and stall front design based on the studies of Ruud et al. (2010a,b, 2011). Even though we report promising results with flexible dividers in the current study, effects of social housing (e.g., cows lying next to each other) or implications of a head-to-head presentation in a normal group-housing situation should be followed up in a future study.

\section{CONCLUSIONS}

The preferences of the cows indicate that they were able to distinguish between types of stall dividers, and that stall divider type is important for them, even though it was not clear if the reason for their choice was the shape or the yielding properties of the dividers. Type of stall divider had no effect on lying behavior. After conducting the present study, we conclude that flexible dividers were more preferred by the cows than fixed ones, with respect to cow behavior.

\section{ACKNOWLEDGMENTS}

The authors thank the participating technicians for their help during the trial and MS student Karen J. Andreassen (Department of Animal and Aquacultural Sciences, Norwegian University of Life Sciences, Ås, Norway) for analyzing all the video films. The study was part of the "Kubygg" project financially supported by grants from the Research Council of Norway (Oslo, Norway), Agricultural Agreement Research Fund (Oslo, Norway), and Foundation for Research Levy on Agricultural Products (Oslo, Norway). The study was approved by the ethical committee at UMB.

\section{REFERENCES}

Aland, A., L. Lidfors, and I. Ekesbo. 2009. Impact of elastic stall partitions on tied dairy cows' behaviour and stall cleanliness. Prev. Vet. Med. 92:154-157.

Anderson, N. G. 2008. Dairy cow comfort-Free stall dimensions. Infosheet. Ministry of Agriculture, Food and Rural Affairs, Ontario, Canada.

Blom, J. Y., S. P. Konggaard, J. G. Larsson, K. Nielsen, A. Northeved, and P. Solfjeld. 1984. Electronic recording of pressure exerted by cows against structures in free-stall housing. Appl. Anim. Behav. Sci. $13: 41-46$

Bramley, M. 1962. Kow kubicles. Part 169, Pages 69-73. Farm Buildings Association, Stowmarket, Suffolk, UK.

CIGR. 1994. The design of dairy cow housing. Report of the CIGR Section II Working group; No 14: Cattle housing. ADAS Bridg- et's Dairy Research Centre Farm Buildings Research Team. Winchester, Hampshire, UK.

Fregonesi, J. A., M. A. G. von Keyserlingk, C. B. Tucker, D. M. Veira, and D. M. Weary. 2009. Neck-rail position in the free stall affects standing behavior and udder and stall cleanliness. J. Dairy Sci. 92:1979-1985.

Fulwider, W. K., and R. W. Palmer. 2004. Use of impact testing to predict softness, cow preference and hardening over time of stall bases. J. Dairy Sci. 87:3080-3088.

Gamroth, M., and S. Stokes. 1999. Freestall housing or not? Pages 63-71 in Proc. Western Dairy Management Conf., Las Vegas, NV. Accessed Aug. 15, 2011. http://www.wdmc.org/1999/FreestallHousing.pdf.

Gwynn, P. E. J., R. Wilkinson, and T. P. Thomas. 1991. Modifying timber cow cubicle divisions to improve cow acceptability. Appl. Anim. Behav. Sci. 28:311-319.

Irish, W. W., and W. G. Merrill. 1986. Design parameters for freestalls. Pages 45-50 in Proc. Dairy Freestall Housing Symp., Harrisburg, PA. NRAES-24. Northeast Regional Agricultural Engineering Service, Ithaca, NY.

Manninen, E., A. M. de Passillé, J. Rushen, M. Norring, and H. Saloniemi. 2002. Preferences of dairy cows kept in unheated buildings for different kind of cubicle flooring. Appl. Anim. Behav. Sci. $75: 281-292$.

McFarland, D. F., and R. E. Graves. 1995. A case study with dairy cattle: Freestalls. Pages 277-293 in Proc. Int. Conf. Animal Behavior and the Design of Livestock and Poultry Systems, Indianapolis, IN. Northeast Regional Agricultural Engineering Service, Ithaca, NY.

Nilsson, C. 1988. Floors in animal houses. Doctoral Diss. Report 61, LBT, Swedish University of Agricultural Sciences, Lund, Sweden.

Nygaard, A. 1983. Kroppsmål hos Norsk Rødt Fe (Body size of Norwegian Red Dairy breed). NLH Rapport intern series no. 388. Institute of Building Technology, Norwegian University of Life Sciences, Ås, Norway.

O'Connell, J. M., P. S. Giller, and W. J. Meaney. 1992. Factors affecting cubicle utilisation by dairy cattle using stall frame and bedding manipulation experiments. Appl. Anim. Behav. Sci. 35:11-21.

Ruud, L. E., K. E. Bøe, and O. Østerås. 2010a. Associations of soft flooring materials in free stalls with milk yield, clinical mastitis, teat lesions, and removal of dairy cows. J. Dairy Sci. 93:15781586.

Ruud, L. E., K. E. Bøe, and O. Østerås. 2010b. Risk factors for dirty dairy cows in Norwegian freestall systems. J. Dairy Sci. 93:52165224 .

Ruud, L. E., C. Kielland, O. Østerås, and K. E. Bøe. 2011. Free-stall cleanliness is affected by stall design. Livest. Sci. 135:265-273.

Sveberg, G., L. E. Ruud, J. Sunde, and O. Østerås. 2007. Mål på NRFkua. (The size of the Norwegian Red Dairy cow). Geno report no. 1/ 07. Geno, Hamar, Norway.

Tucker, C. B., and D. M. Weary. 2004. Bedding on geotextile mattresses: How much is needed to improve cow comfort? J. Dairy Sci. 87:2889-2895.

Tucker, C. B., D. M. Weary, and D. Fraser. 2003. Effects of three types of free-stall surfaces on preferences and stall usage by dairy cows. J. Dairy Sci. 86:521-529.

Tucker, C. B., D. M. Weary, and D. Fraser. 2004. Free-stall dimensions: Effects on preference and stall usage. J. Dairy Sci. 87:1208-1216.

Tucker, C. B., D. M. Weary, and D. Fraser. 2005. Influence of neck-rail placement on free-stall preference, use, and cleanliness. J. Dairy Sci. 88:2730-2737.

Tucker, C. B., G. Zdanowicz, and D. M. Weary. 2006. Brisket boards reduce freestall use. J. Dairy Sci. 89:2603-2607.

Veissier, I., J. Capdeville, and E. Delval. 2004. Cubicle housing systems for cattle: Comfort of dairy cows depends on cubicle adjustment. J. Anim. Sci. 82:3321-3337.

Wandel, H., and T. Jungbluth. 1997. Bewertung neuer Liegeboxenkonstruktionen (Evaluation of a new free stall design). Landtechnik 5:266-267.

Wander, J. F. 1979. Stand-, liege- und verkehrsflächen in Rinderställen. Bauen für die Landwirtschaft 16:9-11. 